\title{
Gençlerin Sosyal Medya Kullanım Amaçları ile Sosyal Medya Bağımlılığı İlişkisinin İncelenmesi
}

\author{
Mehmet Fatih Çömlekçi a, b, Oğuz Başol c
}

Özet

Mevcut araştırma, gençlerin sosyal medyayı en çok hangi amaçlarla ve ne sıklıkla kullanmakta olduğu ile onların sosyal medya kullanım amaçlarıyla sosyal medya bağımlılık düzeyleri arasındaki ilişkiyi ortaya çıarmayı amaçlamaktadır. 763 üniversite öğrencisinin katılımıyla gerçekleştirilen araştırmanın sonuçlarına göre; katılımcılar sosyal medyayı en çok eğlence, iletişim ve gündemi takip etme amaçlarıyla; en az ise kişilere ulaşmak, kişisel sunum ve bilgi paylaşmak ve insanları daha iyi tanımak için kullanmaktadırlar. Bunun yanı sıra araştırma neticesinde gençlerin sosyal medyada günde ortalama 4 saat 16 dakika geçirdikleri tespit edilmiştir. Sosyal medya kullanım amaçları ile sosyal medya bağımlılığı ilişkisi incelendiğinde ise; boş zaman değerlendirmek, insanları daha iyi tanımak, fikir alışverişinde bulunmak, eğlence amaçlı kullanmak, kişilere ulaşmak, kişisel sunum ve bilgi paylaşmak ve mesajlaşmak ile sosyal medya bağımlılığı arasında anlamlı ilişkilerin olduğu görülmüştür. Diğer yandan, iletişim, müzik dinlemek, gündemi takip etmek ve bilgiye erişmek ile sosyal medya bağımlılığı arasında anlamlı bir ilişkinin olmadığı da tespit edilmiştir.

\section{Anahtar Kelimeler \\ Sosyal Medya Bağımlılığı \\ Sosyal Medya Kullanım \\ Makale Hakkında \\ Geliş Tarihi: 11.02.2019 \\ Kabul Tarihi: 20.11.2019 \\ Doi: 10.18026/cbayarsos.525652}

Sosyal Medya İletişim

Amaçları

\section{Analysis of Relationship between Youths' Social Media Usage Motives and Social Media Addiction}

\begin{abstract}
This study aims to reveal the relationship between social media usage motives and social media addiction, youths' major social media usage motives and their social media usage frequency. According to the results of the survey carried out with the participation of 763 university students, the participants mostly use social media for entertainment, communication and keeping up to date. They use social media least to reach people, for self-presentation and information sharing and to get to know people better. When the relationship between social media usage motives and social media addiction analyzed, it is seen that there is a significant relationship between social media addiction and the following social media usage motives: Making use of spare time, getting to know people better, exchange of views, entertainment, reaching people, selfpresentation and information sharing and texting. On the other hand, it is determined that there isn't any significant relationship between social media addiction and the following social media usage motives: Communication, listening to music, keeping up to date and accessing information.
\end{abstract}

Keywords

Social Media

Communication

Social Media Addiction

Social Media Use Motivations

About Article

Received: 11.02 .2019

Accepted: 20.11.2019

Doi: 10.18026/cbayarsos.525652

\footnotetext{
a İletişim Yazarı: fatihcomlekci@gmail.com

b Öğr. Gör. Dr., Kırklareli Üniversitesi Dış İlişkiler Koordinatörlüğü, fatihcomlekci@gmail.com, ORCID: 0000-0002-4811-5558.

c Doç. Dr., Kırklareli Üniversitesi, İktisadi ve İdari Bilimler Fakültesi, Çalışma Ekonomisi ve Endüstri İlişkileri Bölümü, oguzbasol@klu.edu.tr, ORCID: 0000-0002-7523-4544.
} 


\section{Gençlerin Sosyal Medya Kullanım Amaçları ile Sosyal Medya Bağımlılığı İlişkisinin İncelenmesi}

\section{Giriş}

Günümüzde yeni iletişim teknolojileri ve sosyal medya, toplumsal, kültürel, ekonomik ve politik dönüşümleri tetikleyebildiği gibi bireylerin gündelik hayatları ve yaşam tarzları üzerinde de bir takım köklü değişikler yaşanmasına sebep olmaktadır. Bu teknolojilerin enformasyona kolay ve hızlı şekilde ulaşma, zaman-mekan kısıtlarını aşarak iletişim kurma, gündelik hayatı kolaylaştırma gibi faydalarının yanı sıra bir de madalyonun öteki yüzü bulunmaktadır. Kişisel mahremiyetin tehlikeye girmesi, enformasyon yığınından faydalı bilgileri süzmenin zorluğu, manipülatif/yalan haberlerin hızlı biçimde dolaşıma girmesi gibi olumsuz etkilerle birlikte sosyal medya bağımlılığı ile kol kola yürüyen toplumsal hayattan izole yaşam tarzları, akut birer sorun olarak önümüzde durmaktadır.

Papacharissi ve Rubin'in (2000) ortaya attığ gibi, internet ve sosyal medya alternatif bir iletişim mecrası olarak ortaya çıkarken, özellikle kamusal alanda/sosyal çevrede kendini ifade etmekten korku duyan bireyler için bir fırsat olarak belirmiştir. Özelikle gençlerin seslerini duyurabilmeleri, içerik üretmeleri, kendileri gibi düşünen insanlarla bir araya gelerek ağlar oluşturabilmeleri ve politik ve toplumsal konularda fikirlerini ortaya koyarak demokratik katılımlarını arttırmaları gibi olanaklar sağlayan sosyal ağlar bu bağlamda olumlu etkiler de yapmıştır. Ancak internet ve sosyal medya öncesinde sosyal hayatta giderilen iletişim, kendini ifade etme ve eğlence gibi ihtiyaçların sanal ortama aktarılması, sosyal medyaya olan bağımlılığı tetikleyebilmekte ve kişilerin toplumsal hayattan izole bir biçimde yaşayarak bazı ruhsal sorunlar yaşamalarına neden olabilmektedir.

İşte bu bağlamda çalışmanın amacı, gençlerin (üniversite öğrencilerinin) sosyal medya kullanım amaçlarını ve sosyal medya bağımlılık düzeylerini ölçerek, belirli sosyal medya kullanım amaçlarının/alanlarının sosyal medya kullanım bozukluğu ya da bağımlılığı ile ilişkide olup olmadığını tespit etmektir. Bu çerçevede Kırklareli Üniversitesi öğrencileri ile anket yoluyla yapılan araştırmada, üniversite öğrencilerinin günde kaç saatlerini sosyal medyada harcadıkları, yoğunlukla hangi sosyal medya platformlarını kullandıkları, haber almak için hangi sosyal medya mecralarını tercih ettikleri gibi bilgiler araştırmayı destekleyici biçimde ortaya konmuştur. Literatür kısmında sosyal medya kullanımı ve sosyal medya bağımlılığı ile ilgili dünyadaki son araştırma, istatistik ve ölçümlere yer verilmiş olmakla birlikte; araştırmanın asıl amacı Türkiye'deki gençlerin sosyal medya bağımlılığı sorunu ile ilgili güncel bir değerlendirme yapmak olduğundan, çalışma esas olarak Türkiye'deki literatürdeki boşluğu doldurmayı ve güncel bir ölçüm yapmayı hedeflemektedir.

Literatürde gençlerin internet ve sosyal medya kullanım alışkanlıklarını (Koçer, 2012; Tektaş, 2014; Aydın, 2016; Solmaz ve diğerleri, 2013; Köseoğlu, 2012; Küçükali, 2016) ve sosyal medya bağımlılık düzeylerini (Şahin ve Yağcı, 2017; Çelik, 2017; Kırık ve diğerleri, 2015) ayrı ayrı ele alan çalışmalar; sosyal medya bağımlılığı ile sosyal medyanın eğitsel amaçlı kullanımını inceleyen (Yılmazsoy ve Kahraman, 2017), sosyal medya kullanım alanları ile sosyal medya bağımlılığı ilişkisini teorik düzeyde inceleyen (Babacan, 2016) araştırmalar bulunmakla birlikte, gençlerin sosyal medyayı hangi amaçlarla kullandıkları ile sosyal medya bağımlılık düzeyleri arasındaki ilişkiyi ampirik yöntemlerle ele alan sınırlı sayıda çalışma bulunmaktadır. Bu anlamda öne çıkan araştırmalar, Akın'ın (2017) Ömer Halisdemir Üniversitesi öğrencileri ile ve Filiz ve diğerlerinin (2014) Bilgisayar ve Öğretim Teknolojileri Eğitimi bölümü öğrencileriyle gerçekleştirdikleri çalışmalardır. Filiz ve diğerlerinin (2014) araştırmasında sosyal medya kullanım amaçları ve bağımlılığı çerçevesinde kadın ve erkek 
kullanıcılar arasındaki farklar da ele alınmıştır. Mevcut çalışma ise, gençlerin sosyal medya kullanım amaçları ile bağımlılık düzeyleri arasındaki ilişkinin geniş bir örneklem ile güncel olarak ele alınıp ölçülmesi, elde edilen sonuçların literatürdeki güncel gelişmeler ışığında tartışılması ve ulaşılan sonuçlar bağlamında sosyal medya bağımlılı̆̆ını sınırlayabilmek adına bazı öneriler sunulması hedeflenmektedir.

\section{Sosyal Medya Kullanımı ve Sosyal Medya Bă̆ımlılı̆̆ı}

Çevrim içi sosyal medya siteleri Boyd ve Ellison'un (2007) tanımlamasıyla, kullanıcılara diğer insanlara açık (ya da seçilenlere) profiller oluşturma, diğer kullanıcılarla ve onların bağlantıda olduğu kişilerle ağ üzerinde bağlantılı ve etkileşim içinde olma imkanı veren web tabanlı platformlardır. Bu platformlarda kullanıcılar sanal kimlikler oluşturabilir, gerçek hayattaki arkadaşları ile etkileşime girebilir ve kendilerine benzer ilgi alanları olan kişilerle hem çevrim içi hem de çevrim dışı ortamda sosyal ilişki tesis edebilirler (Griffiths, 2012; Kuss ve Griffiths, 2011). Sosyal medya kullanımı sosyal ve politik katılım, kendini iyi hissetme, yalnızlığa çare gibi amaçlarla da kullanılmakta, ancak bu anlamda sosyal ağlara aşırı biçimde yaslanma sosyal medya bağımlılı̆̆ını besleyen bir unsur olabilmektedir (Babacan, 2016). Ayrıca günümüzde sosyal medya, halkla ilişkiler, pazarlama, alışveriş, reklamcılık, habercilik, siyasi kampanya, sivil toplum örgütü çalışmaları gibi çok çeşitli alanlarda işlevsel bir konumdadır.

We Are Social'ın 2018 Dijital Raporuna göre (Kemp, 2018), dünyada 4.021 milyar internet kullanıcısı, 3.196 milyar aktif sosyal medya kullanıcısı (dünya nüfusunun \%42'si) ve 2.958 milyar aktif mobil sosyal medya kullanıcısı bulunmaktadır. Bir önceki yıla göre internet kullananların sayısı \%7 oranında artarken, sosyal medya kullananların sayısı \%13, mobil sosyal medya kullanıcılarının sayısı ise \%14 oranında artmıştır. Bu tabloya göre, sosyal ağlar üzerindeki popülasyon her geçen gün daha da genişlemekte, her gün ortalama 1 milyon kişi yeni sosyal medya hesapları açmakta, sosyal medya platformlarını ve mobil telefon üzerinden sosyal medyayı aktif olarak kullanmayan internet kullanıcılarının sayısı da azalmaktadır. Dünyada ortalama bir kullanıcı 2018 yılı itibarıla internette günde ortalama 6 saate yakın zaman geçirmekteyken, Türkiye' de ise ortalama internet kullanım süresi 7 saat 9 dakika, sosyal medya kullanım süresi ise 2 saat 48 dakika olarak ölçülmektedir. Ayrıca, Türkiye' de 2018 yılı itibarıyla 51 milyon sosyal medya kullanıcısı bulunmaktadır ve bu sayı 2017 yılına göre \%6 oranında artmıştır. Türkiye'de en çok kullanılan sosyal medya platformları sirasiyla Youtube, Facebook ve Instagram'dır ve Türkiye Instagram kullanımında dünyada 6. sırada bulunmaktadır. Yine We Are Social 2018 Dijital Raporuna (Kemp, 2018) göre Türkiye'de yeni iletişim teknolojilerinin riskten çok yeni olanaklar getireceğini düşünen "dijital iyimserler" in oran \%70 seviyesindedir.

Tüm dünyada ve Türkiye'de sosyal medya kullanımının arttığı ve bu sürece iyimser yaklaşanlar olduğu bilinmekle birlikte, bu durumun getirdiği bazı olumsuz sonuçlar ve riskler de bulunmaktadır. Kişisel mahremiyetin ihlali, kullanıcı bilgilerinin sosyal medya platformları tarafından depolanması, siber saldırılar, siber zorbalık ve taciz gibi risklerin yanında sosyal medya bağımlılığı da son dönemde sıklıkla tartışılan bir konu olarak ortaya çıkmaktadır.

Andreassen ve diğerleri (2014) sosyal medya bağımlılığını, "sosyal medya mecralarıyla aşırı meşgul olma, bu platformlara sürekli bağlı kalmak için yoğun bir istek duyma ve bu mecralarda sosyal hayattaki diğer aktiviteleri, öğrencilik/iş hayatını, kişilerarası iletişimi ve 


\section{Gençlerin Sosyal Medya Kullanım Amaçları ile Sosyal Medya Bağımlılığı İlişkisinin İncelenmesi}

ruh durumunu zedeleyecek kadar çok zaman harcama" durumu olarak tanımlamıştır. Davranışsal bağımlılık konularında en büyük tartışma, aşırı kullanımların (video oyunları, internet, vb.) bağımlılık olarak addedilip addedilemeyeceğidir. Sosyal medya bağımlılığı konusundaki benzer bir tartışma bağlamında Griffiths (2005), aşırı kullanımın bağımlılık sayılabilmesi için altı öğenin birlikte varlığının şart olduğunu ileri sürmüştür:

Belirleyicilik: Sosyal medya kullanımının kişinin hayatındaki tek önemli aktivite haline gelmesi ile düşünce, duygu ve davranışlarına egemen olması. Sosyal ağlarda zaman geçirilmediği anlarda bile sürekli çevrim içi olunacak anı düşünmek.

Ruh Hali Değişikliği: Kişilerin aşırı sosyal medya kullanımı neticesindeki sübjektif deneyimleri ve bununla başa çıkma yöntemleri. Örneğin kendini gereğinden çok daha iyi hissetme, ya da tersine hissizleşme.

Tolerans: Sosyal medya kullanımı neticesinde elde edilen ruh haline tekrar kavuşmak için kullanımı (sosyal medyada geçirilen süreyi) daha da arttırma.

Yoksunluk Semptomları: Kişilerin hasta olmaları, tatilde olmaları vb. sebeplerle sosyal medyaya erişememeleri nedeniyle ortaya çıkan nahoş duygu durumları ve/veya karamsarlık, asabiyet gibi fiziksel etkiler.

Çatışma: Kişinin sosyal medyada çok fazla zaman geçirmesi sonucunda çevresindeki insanlarla, diğer sosyal aktiviteler bağlamında (hobiler, diğer ilgi alanları) ve kendi içerisinde yaşadığı çatışmalar.

Döngü: Yoğun sosyal medya kullanımı sonrasında önceki safhalarda oluşan tüm belirtilerin tekrar etmesi, kısa süreli kontrol anlarından sonra belirtilerin artarak ilerlemesi.

Yeni iletişim teknolojilerinin olası olumsuz etkilerine karşı en hassas grup, bu teknolojilere hızlıca adapte olarak onları kolayca gündelik hayatlarının birer parçası haline getiren "dijital yerliler" (Palfrey ve Gasser, 2008), yani gençlerdir (Valkenburg ve Peter, 2011; Echeburua ve de Corral, 2010; Utz ve diğerleri, 2015). Bu bağlamda internet bağımlılı̆ğ ile büyük ölçüde ilişkili kabul edilen "oyun oynama" ve "sosyal medya kullanımı" genç kesim arasında ön plana çımaktadır (Rumpf ve diğerleri, 2011; Van Rooij ve diğerleri, 2010). Davies ve Cranston'un (2008) 120 gençlik merkezi yöneticisi ile yaptıkları ankette, sosyal medyanın diğer çevrim dışı aktiviteler ve yüz-yüze iletişimin yerini alacağı korkusunun gençler arasında yaygın olduğu sonucuna varmıştır. Yine bu ankette sosyal medya bağımlılığının (\%23) yanında, siber zorbalık (\%53), kişisel bilgilerin ifşası (\%35) ve çevrim içi taciz sosyal ağların getirdiği riskler olarak sıralanmıştır. Lee, Cheung ve Thadani (2012) ise, sosyal medyanın aşırı düzeyde kullanımının gençlerin hayatında psikolojik, sosyal ve okul/üniversite bağlantılı problemler yaratabileceğini ortaya koymuştur. Bunun yanında, yetişkin akıllı telefon kullanıcılarının takıntı derecesindeki sosyal medya kullanımlarının giderek artan bir ruh sağlığı sorunu olduğu yönünde ampirik kanıtlar da bulunmaktadır (Van Rooij ve Schoenmakers, 2013; Pantic, 2014; Ryan ve diğerleri, 2014). 2017 yılında İtalya'da sosyal medya kullanıcıları üzerinde yapılan bir araştırmada ise, katılımcıların \%67'sinin çevrim içi ağlara bağlı olmadıklarında "bir şeyleri kaçırdıkları" korkusu yaşadıkları, \%66'sının sosyal medyada fazla zaman geçirdiklerinde uyku problemi yaşadıkları, \%50'sinin hayat kalitelerinde düşüş olduğu ve $\% 25^{\prime}$ inin e-postalarını ya da Facebook mesaj kutularını kontrol etmediklerinde huzursuz oldukları sonucu ortaya çıkmıştır (Statista, 2019). 
$\mathrm{Bu}$ çerçevede literatürde sosyal medya kullanım amaçları ile sosyal medya bağımlılığını inceleyen çalışmalara yakından bakmak faydalı olacaktır. Filiz ve diğerlerinin (2014) lisans öğrencilerinin sosyal ağ siteleri kullanım amaçları ile internet bağımlılığı ilişkisini inceledikleri araştırmada, sosyal ağların etkileşim ve iletişim, tanıma ve tanınma ve eğitim amaçlı kullanımları ile internet bağımlılığı arasında düşük düzeyde pozitif yönde bir ilişki gösterdiği belirlenmiştir. Ayrıca söz konusu çalışmada, erkekler ile kadınlar arasında sosyal medya kullanım amaçları (tanıma ve tanınma) açısından anlamlı bir farklılık olduğu, ancak internet bağımlılığının cinsiyete göre herhangi bir farklılık göstermediği tespit edilmiştir. Akın'ın (2017) Ömer Halisdemir Üniversitesinde eğitim-öğretim gören 756 öğrenci ile yaptığ anket çalışmasında ise, gençlerin temel olarak sosyal medyayı iletişim, fotoğraf ve video paylaşımı amacıyla kullandıkları ve sırasıyla Facebook, Twitter, Instagram ve Youtube platformlarını tercih ettikleri; bu kullanım amaçlarının sosyal medya bağımlılı̆̆ı ile ilişkili olduğu sonucuna varmışlardır.

Sofiah ve diğerleri (2011) yaşları 19-28 arasında değişen 380 Malezyalı kadın üniversite öğrencisiyle Facebook bağımlılı̆̆ı ile ilgili yaptıkları araştırmada, sosyal etkileşim, eğlence, boş zaman geçirme, arkadaşlık ve iletişim isteği ile Facebook kullanımı ve bağımlılığ arasında anlamlı bir ilişki olduğu ortaya koyulmuştur. Söz konusu ilişkiye yakından bakıldığında, boş zaman geçirme isteğinin Facebook bağımlılığını etkileyen en önemli faktör olduğu, onu eğlence ve iletişim isteğinin izlediği görülmüştür. Ryan ve diğerlerinin (2014) Facebook özelinde yaptıkları araştırma da benzer şekilde kişilerin en çok arkadaşlık ağlarını koruma, boş zaman geçirme, eğlence ve arkadaşlık amaçlarıyla Facebook'u kullandıkları, bu kullanımları ile sosyal medya bağımlılığı arasında pozitif bir ilişki olduğu ortaya koyulmuştur.

Floros ve Siomos'un (2013) Yunanistan'daki lise öğrencileri ile yaptığ 1 ve sosyal medya kullanım ölçeği ile sosyal medya kullanım bozuklukları ilişkisini incelediği araştırmada ise, öğrencilerin sosyal ağlarda yoğun zaman geçirmesinin "arkadaşlarıyla sürekli iletişim halinde kalabilme" isteği ile ilişkili olduğu sonucuna varılmıştır. Wan'ın (2009) 335 Çinli üniversite öğrencisi ile "xiaonei.com" sosyal medya uygulaması özelinde yaptığı araştırmada ise, sosyalleşme ve sanal ortamda ilişki geliştirme isteğinin bu sosyal platformun aşırı derecede kullanımına yol açtığını gösterilmiştir. Punyanunt-Carter ve diğerlerinin $(2017,870)$ bir sosyal medya uygulaması olan Snapchat kullanıcısı ABD'deki 475 üniversite öğrencisinin katılımıyla gerçekleştirdikleri çalışmada, kullanıcıların eğlence isteklerinin tatmini ile sosyal medya olan bağımlılıkları arasında pozitif bir ilişki olduğu ortaya koyulmuştur. Chen ve Kim (2013) de çalışmalarında benzer şekilde, aşırı sosyal medya kullanımı ile eğlence ve kendini ifade etme amacıyla sosyal medyanın kullanımı arasında bir ilişki olduğunu ifade etmişlerdir.

\section{Araştırmanın Amacı ve Temel Soruları}

Giriş bölümünde de detaylı biçimde ifade edildiği gibi çalışmanın amacı, gençlerin (üniversite öğrencilerinin) sosyal medya kullanım amaçlarını ve sosyal medya bağımlılık düzeylerini ölçerek, belirli sosyal medya kullanım amaçlarının/alanlarının sosyal medya kullanım bozukluğu ya da bağımlılığı ile ilişkide olup olmadığını tespit etmektir.

Araştırmanın iki temel sorusu bulunmaktadır. Bunlar; “Gençler sosyal medyayı en çok hangi amaçlarla ve ne sıklıkla kullanmaktadır?" ve "Gençlerin sosyal medya kullanım amaçlarıyla sosyal medya bağımlılık düzeyleri arasında bir ilişki mevcut mudur?" sorularıdır. 


\section{Gençlerin Sosyal Medya Kullanım Amaçları ile Sosyal Medya Bağımlılı̆̆ı İlişkisinin İncelenmesi}

\section{Yöntem}

Araştırmada anket yöntemi kullanılmıştır. Verilerin çözümlenmesinde iki ayrı istatistik programından faydalanılmıştır. Bu programlardan ilki SPSS 22.0 paket programıdır. $\mathrm{Bu}$ program aracılığıyla; tanımlayıcı istatistiklere yer verilmiş, normal dağılım analizi, KruskallWallis $\mathrm{H}$ ve Spearman korelasyon testi sonuçları değerlendirilmiştir. Kullanılan ikinci program ise LISREL 8.71 paket programıdır. Bu program ise doğrulayıcı faktör analizini gerçekleştirmek için kullanılmıştır. Devam eden bölümde araştırmanın örneklemine ve kullanılan ölçüm araçlarına ilişkin bilgilere yer verilmiştir.

\section{Araştırmanın Örneklemi}

Araştırmanın evreni Kırklareli Üniversitesi'nde eğitim alan gençlerdir. Öğrenci İşleri Daire Başkanlığı ile gerçekleştirilen görüşme sonrasında üniversitede eğitim alan 26.000 öğrenci bulunduğu öğrenilmiştir. Bahsi geçen evreni temsil eden örneklem büyüklüğünün 379 olduğu tespit edilmiştir (https://www.surveysystem.com/sscalc.htm).

Anket uygulamaya geçmeden önce 30 kişilik bir öğrenci grubu ile pilot çalışma gerçekleştirilmiştir. Pilot çalışmada anketin amacı katılımcılarla paylaşılmış ve soruların anlaşılma düzeyi tartışılmıştır. Akabinde bahsi geçen öğrenci grubuna anket uygulanmış ve sonuçlar değerlendirilmiştir. Elde edilen bulgular anketlerin çalıştı̆̆ını göstermiş ve veri toplama sürecine geçilmiştir.

Üniversiteden gerekli uygulama izinleri alındıktan sonra üniversite bünyesindeki tüm kampüslerde (meslek yüksekokulları, yüksekokullar, fakülteler ve enstitülerde) gönüllülük esasına göre öğrencilere anket uygulaması 3 Aralık 2018 tarihleri ile 4 Ocak 2019 tarihleri arasında gerçekleştirilmiş ve toplam 801 kişi ankete katılmıştır. Ancak, gerçekleştirilen inceleme sonrasında 38 anket formunun eksik olduğu belirlenmiş ve değerlendirme dışı bırakılmış, 763 katılımcının verdiği yanıtlar değerlendirmeye alınmıştır.

\section{Araştırmada Kullanılan Ölçüm Aracı}

Araştırmada kullanılan anket formu 3 bölüm ve 24 sorudan oluşmaktadır. Buna göre; ilk bölüm 2 alt başlıktan oluşmaktadır. İlk alt başlık katılımcıların demografik özelliklerini belirlemeye yöneliktir ve ilgili bölümde 3 soru bulunmaktadır (cinsiyet, yaş ve aylık harcama). İkinci alt başlık ise sosyal medya platformları ile ilgilidir ve bu bölümde 3 soru bulunmaktadır (sosyal medyada geçirilen süre, en sık kullanılan sosyal medya hesabı ve haberleri en çok hangi sosyal medya mecrasından aldığı).

İkinci bölümde sosyal medya kullanım amaçlarını ölçmek için Solmaz ve diğerleri (2013) tarafından geliştirilen, mevcut araştırmada geçerlik-güvenirlik çalışması yapılan "sosyal medya kullanım amaçları" (Ek-1) ölçeği kullanılmıştır (örnek madde: sosyal medyayı bilgiye erişim amacıyla kullanırım). Solmaz ve diğerleri (2013) tarafından geliştirilen ölçekte 14 madde bulunmaktadır. Ancak yapılan geçerlik-güvenirlik çalışması sonucunda 3 maddenin değerlendirme dışı bırakılmasına karar verilmiştir. Böylece ölçüm aracı 11 maddelik hale gelmiştir. LISREL 8.71 programı ile doğrulayıcı faktör analizi işlemi gerçekleştirilmiştir. Analiz sonuçları, ölçeğin standartlaştırılmış yüklerinin 0.57 ile 0.60 arasında olduğunu ve tüm değerlerin anlamlı olduğunu $(t>1.96)$ göstermiştir. Ayrıca, gerçekleştirilen analiz sonrasında ölçeğin geçerli ve güvenilir bir ölçek olduğu da tespit edilmiştir ( $\chi 2$ /sd: 179.50/44: 4.07, RMSEA: 0.074, NFI: 0.91, NNFI: 0.95, CFI: 0.95, GFI: 0.91, AGFI: 0.88). Bu bölümdeki maddeler 5'li Likert tipi değerlendirme ile ölçülmüştür (1= Hiçbir zaman; 2= Nadiren; 3= 
Bazen; 4= Sıklıkla; 5= Her zaman). Gerçekleştirilen analiz sonrasında, sosyal medya kullanım amaçları ölçeğinin içsel tutarlığının (Cronbach's Alpha) 0.819 olduğu tespit edilmiştir. Bulgular kısmındaki verilerin analizi için SPSS 22.0 paket programı kullanılmıştır

Üçüncü bölümde ise Günüç (2009) tarafından geliştirilen ve geçerlik-güvenirlik çalışması yapılan internet bağımlılı̆̆ı ölçeğinin alt boyutu olan işlevsellikte bozulma kısmı (Ek-2) kullanılmıştır. Ölçekte 7 madde bulunmaktadır ve bu ölçekteki maddeler internet bağımlılığı yerine sosyal medya bağımlılı̆̆ı şeklinde revize edilmiştir (örnek madde: sosyal medyayı kullanmamdan dolayı ailem ile sorunlar yaşarım). Revizyon sonrasında LISREL 8.71 programı ile doğrulayıcı faktör analizi işlemi gerçekleştirilmiştir. Analiz sonuçları, ölçeğin standartlaştırılmış yüklerinin 0.52 ile 0.86 arasında olduğunu ve tüm değerlerin anlamlı olduğunu ( $(>1.96)$ göstermiştir. Ayrıca, gerçekleştirilen analiz sonrasında ölçeğin geçerli ve güvenilir bir ölçek olduğu da tespit edilmiştir ( $\chi 2$ /sd: 54.40/14: 3.88, RMSEA: 0.078, NFI: 0.96, NNFI: 0.95, CFI: 0.96, GFI: 0.95, AGFI: 0.89). Bu bölümdeki maddeler 5'li Likert tipi değerlendirme ile ölçülmüştür (1= Hiçbir zaman; 2= Nadiren; 3= Bazen; 4= S1klıkla; 5= Her zaman). Gerçekleştirilen analiz sonrasında, sosyal medya bağımlılık ölçeğinin içsel tutarlığının (Cronbach's Alpha) 0.850 olduğu tespit edilmiştir. Bulgular kısmındaki verilerin analizi için SPSS 22.0 paket programı kullanılmıştır.

\section{Bulgular}

Araştırmaya 438 kadın (\%57.4) ve 325 erkek (\%42.6) öğrenci olmak üzere toplam 763 kişi katılmıştır. Katılımcıların yaşları 18 ile 28 arasında değişmekte olup ortalaması 20 yaş (ss 1.94) olarak gerçekleşmiş, aylık harcamaları ise 150 TL ile 2500 TL arasında değişmekte olup ortalaması 788 TL (ss 453.56) olarak hesaplanmıştır.

Katılımcıların sosyal medya platformları ile ilgili görüşleri incelendiğinde; öğrencilerin günde 1 ile 15 saat arasında sosyal medyada zaman geçirdikleri ve günde ortalama 4 saat 16 dakika (ss 2.52) sosyal medyada bulundukları görülmüştür. En sık kullanılan sosyal medya hesapları incelendiğinde; sırayla Instagram (527 kişi, \%69.1), Youtube (120 kişi, \%15.7), Twitter (46 kişi, \%6), Facebook (41 kişi, \%5.4), Tumblr, Google ve Bundle gibi diğer (29 kişi, \%3.8) sosyal medya hesaplarını kullandıkları görülmüştür. Haberlerin ise sırasıyla Instagram (377 kişi, \%49.4), Twitter (148 kişi, \%19.4), Youtube (112 kişi, \%14.7), Google, Bundle, memurlar.net gibi diğer (71 kişi, \%9.3) ve Facebook (55 kişi, \%7.2) üzerinden alındığ tespit edilmiştir. Buradan hareketle Instagram'ın hem en sık kullanılan hem de en sık haber alınan sosyal medya kaynağı olduğu görülmüştür.

Tablo 1. Sosyal Medya Kullanım Amaçlarına İlişkin Bilgiler

\begin{tabular}{lccc}
\hline & Ortalama & $\begin{array}{c}\text { Standart } \\
\text { sapma }\end{array}$ & $\begin{array}{c}\text { Kolmogorov- } \\
\text { Smirnov Z } \\
\text { Değeri }\end{array}$ \\
\hline Eğlence & 3.76 & 1.07 & 7.17 \\
İletişim & 3.67 & 1.10 & 6.75 \\
Gündemi takip etmek & 3.59 & 1.06 & 7.00
\end{tabular}


Mesajlaşmak

Boş zaman değerlendirmek

Bilgiye erişmek

Müzik dinlemek

Fikir alışverişinde bulunmak

Kişilere ulaşmak

Kişisel sunum ve bilgi paylaşmak

Insanları daha iyi tanımak
3.52

3.52

3.35

3.34

2.89

2.83

2.68

2.56
1.16

1.08

1.13

1.26

1.07

1.13

1.14

1.20
5.77

6.04

5.54

5.91

5.77

4.77

4.86

5.02

Tablo 1, katılımcıların, sosyal medya kullanım amaçlarına ilişkin bulguları göstermektedir. Buna göre, katılımcıların sosyal medyayı en çok eğlence, iletişim ve gündemi takip etme amacıyla kullandıkları, en az ise kişilere ulaşmak, kişisel sunum ve bilgi paylaşmak ve insanları daha iyi tanımak için kullandıkları tespit edilmiştir. Ayrıca gerçekleştirilen normal dağılım analizi sonrasında, sosyal medya kullanım amaçlarının maddelerinin tümünün normal dağılıma uygun olmadığı tespit edilmiştir $(\mathrm{p}<0.05)$. Bu sebeple amaçlara ilişkin gerçekleştirilen analizlerde parametrik olmayan testler kullanılmıştır.

Tablo 2. En Sık Kullanılan Sosyal Medya Hesaplarında Geçirilen Süre

\begin{tabular}{lcccc}
\hline \multicolumn{1}{c}{ Sosyal Medya } & Ortalama & Standart sapma & Chi-Square & Fark nedeni \\
\hline I. Instagram & $260 \mathrm{dk}$. & 2.56 & & \\
II. Twitter & $241 \mathrm{dk}$. & 3.07 & & \\
III. Facebook & $204 \mathrm{dk}$. & 1.92 & 13.034 & I $>$ III \\
IV. Youtube & $236 \mathrm{dk}$. & 2.38 & \\
V. Diğer & $226 \mathrm{dk}$. & 1.93 & \\
\hline
\end{tabular}

Tablo 2, en sık kullanılan sosyal medya hesaplarında geçirilen süreye ilişkin bulguları göstermektedir. Analiz sonuçları, katılımcıların en sık kullandıkları sosyal medya hesaplarına göre sosyal medyada geçirdikleri sürenin birbirinden farklılaşmakta olduğunu göstermiştir (Chi-Square: 13.034, p: 0.01). Ortaya çıkan bu farklılığın istatistiki nedeni incelendiğinde; farklılaşmanın nedeninin, Instagram'da geçirilen süreyle Facebook'da geçirilen süre arasındaki fark olduğu görülmüştür. Buna göre katılımcılar Instagram'da Facebook'a kıyasla yaklaşık 1 saat daha fazla zaman geçirmektedir. 
Tablo 3. Sosyal Medya Haber Alma Kanallarında Geçirilen Süre

\begin{tabular}{lcccc}
\hline \multicolumn{1}{c}{ Sosyal Medya } & Ortalama & Standart sapma & Chi-Square & Fark nedeni \\
\hline I. Instagram & $273 \mathrm{dk}$. & 2.67 & & \\
II. Twitter & $252 \mathrm{dk}$. & 2.47 & & \\
III. Facebook & $226 \mathrm{dk}$. & 2.15 & 14.071 & $\mathrm{I}>\mathrm{V}$ \\
IV. Youtube & $231 \mathrm{dk}$. & 2.38 & & \\
V. Diğer & $221 \mathrm{dk}$. & 2.11 & & \\
\hline
\end{tabular}

Tablo 3, sosyal medya haber alma kanallarında geçirilen süreye ilişkin bulguları göstermektedir. Analiz sonuçları, katılımcıların en sık haber almak için kullandıkları sosyal medya hesaplarına göre sosyal medyada geçirdikleri sürenin birbirinden farklılaşmakta olduğunu göstermiştir (Chi-Square: 14.071, p: 0.00). Ortaya çıkan bu farklılı̆̆ın istatistiki nedeni incelendiğinde; farklılaşmanın nedeninin, Instagram'da haber almak için geçirilen süreyle diğer sosyal medya kanallarında haber almak için geçirilen süre arasındaki fark olduğu görülmüştür. Buna göre katılımcılar Instagram'da, diğer sosyal medya kanallarına göre yaklaşık 1 saat daha fazla haber almak amaciyla zaman geçirmektedir.

Tablo 4. Sosyal Medya Kullanım Amaçları ve Sosyal Medya Bağımlılığı İlişkisi

SMB

Sosyal Medya Bağımlılığı (SMB)

1,000

Günlük ortalama saat

$0.305^{* *}$

İletişim

0.023

Eğlence

$0.141^{* *}$

Boş zaman değerlendirmek

$0.216^{* *}$

Müzik dinlemek

$-0.029$

Mesajlaşmak

$0.085^{*}$

İnsanları daha iyi tanımak

$0.187^{* *}$

Gündemi takip etmek

$-0.004$

Kişisel sunum ve bilgi paylaşmak

$0.085^{*}$

Kişilere ulaşmak

$0.088^{*}$

Fikir alışverişinde bulunmak

$0.158^{* *}$

Bilgiye erişmek

0.023

Elde edilen bulgular, Spearman's rho değerleridir. ${ }^{*} \mathrm{p}<0.05 \quad{ }^{* *} \mathrm{p}<0.01$

Tablo 4, sosyal medya kullanım amaçları ve sosyal medya bağımlılığı ilişkisine dair sonuçları 


\section{Gençlerin Sosyal Medya Kullanım Amaçları ile Sosyal Medya Bağımlılı̆̆ı İlişkisinin İncelenmesi}

göstermektedir. Analiz sonuçlarına göre sosyal medyada geçirilen zaman ile sosyal medya bağımlılığı arasında pozitif bir ilişki söz konusudur (r: 0.305, p<0.01). Diğer bir ifade ile bireylerin sosyal medyada geçirdikleri zamanın artması bilinçli ya da bilinçsiz bir şekilde sosyal medya bağımlılı̆̆ını arttıran bir etmendir. Analiz sonucunda önemli bir bulgu ortaya çıkmıştır. Buna göre, boş zaman değerlendirmek için sosyal medya kullanımı ile sosyal medya bağımlılığı arasında pozitif bir ilişki söz konusudur ( $\mathrm{r}$ : 0.216, $\mathrm{p}<0.01$ ). Benzer bir durum; insanları daha iyi tanımak ( $\mathrm{r}$ : 0.187, $\mathrm{p}<0.01)$, fikir alışverişinde bulunmak ( $\mathrm{r}: 0.158$, $\mathrm{p}<0.01$ ), eğlence amaçlı kullanmak ( $\mathrm{r}: 0.141, \mathrm{p}<0.01)$, kişilere ulaşmak (r: 0.088, p<0.05), kişisel sunum ve bilgi paylaşmak ( $\mathrm{r}: 0.085, \mathrm{p}<0.05)$ ve mesajlaşmak $(\mathrm{r}: 0.085, \mathrm{p}<0.05)$ için de geçerlidir. Buna göre sosyal medyayı, boş zaman değerlendirmek, insanları daha iyi tanımak, eğlence amaçlı gibi nedenlerle kullanmak ile sosyal medya bağımlılığı arasında pozitif bir ilişki bulunmaktadır. Diğer yandan, iletişim, müzik dinlemek, gündemi takip etmek ve bilgiye erişmek ile sosyal medya bağımlılığı arasına anlamlı bir ilişkinin olmadığı da tespit edilmiştir ( $>0.05)$. Buradan hareketle sosyal medyayı spesifik amaçla kullanma (örneğin; iletişim, gündemi takip etme) ile sosyal medya bağımlılığı arasında bir ilişki bulunmazken, sosyal medyayı boş zamanı değerlendirmek ya da eğlence amaçlı kullanım ile sosyal medya bağımlılı̆̆ı arasında pozitif bir ilişki olduğu görülmüştür. Diğer bir ifade ile sosyal medyayı bir amaç ve bilinç ile kullanmak sosyal medya bağımlılığı yaratmazken, zamanı doldurmak için kullanmak sosyal medya bağımlılığıyla ilişkili bir amaç olarak ortaya çıkmıştır.

Tablo 5. Sosyal Medyada Geçirilen Ortalama Süre ve Bağımlılık Düzeyinin Cinsiyete Göre Farklılaşmasına İlişkin Bulgular

\begin{tabular}{cccccc}
\hline & Cinsiyet & Ortalama & Ss & M-W U & p \\
\hline \multirow{2}{*}{ Ortalama saat } & Kadın & $272 \mathrm{dk}$. & 2.61 & & \\
& Erkek & $232 \mathrm{dk}$. & 2.34 & -4.121 & 0.00 \\
\multirow{2}{*}{ Bağımlılık } & Kadın & 1.72 & 0.70 & & \\
& Erkek & 1.76 & 0.81 & -0.161 & 0.87 \\
\hline
\end{tabular}

M-W U: Mann-Whitney U Test sonucunu göstermektedir.

Tablo 5, sosyal medyada geçirilen ortalama süre ve bağımlılık düzeyinin cinsiyete göre farklılaşmasına ilişkin bulguları göstermektedir. Buna göre kadınların erkeklere kıyasla sosyal medyada günde 40 dakika daha fazla zaman geçirdikleri tespit edilmiştir (Z: -4.121, p: 0.00). Ayrıca, kadınların ve erkeklerin sosyal medya bağımlılık seviyeleri arasında anlamlı bir farklılık bulunmamaktadır (Z: -0.161, p: 0.87). Buna göre, kadınlar sosyal medyayı daha fazla kullanırken, cinsiyet bağımlılık üzerinde fark yaratan değişken konumunda değildir.

İlaveten, kadınların ve erkeklerin sosyal medya kullanım amaçları arasındaki farklılıklar incelendiğinde tüm kullanım amaçları için cinsiyete dayalı bir farklılık olmadığı görülmüştür $(p<0.05)$. Diğer bir ifade ile sosyal medyayı fikir alışverişinde bulunmaktan, eğlence amaçlı kullanmaya; kişilere ulaşmaktan, boş zamanı değerlendirmeye kadar tüm kullanımların kadınlar ve erkekler için istatistiki olarak eşit düzeyde gerçekleştiğini söylemek yerinde olacaktır. 


\section{Tartışma, Sonuç ve Öneriler}

Öncelikle, araştırma neticesinde üniversite öğrencilerinin sosyal medyada günde ortalama 4 saat 16 dakika geçirdikleri, bunun Türkiye ortalaması olan 2 saat 48 dakikanın (Kemp, 2018) epey üstünde olduğu görülmüştür. Bu sonuç, gençlerin diğer yaş gruplarına göre sosyal medyada daha fazla zaman geçirdiklerini göstermektedir. Ek bir bulgu olarak, kadınların erkeklere göre sosyal medyada 40 dakika daha fazla zaman harcadıkları görülmüştür. Gençlerin en çok kullandığı ve zaman geçirdiği (Facebook'a göre 1 saat fazla) sosyal medya uygulaması ise "Instagram" olarak ortaya çıkmış, bu durumun hem gençlerin sosyal medyayı çoğunlukla "eğlence" ve "boş zaman geçirme" amacıyla kullanmaları bulgusu, hem de Türkiye' nin Instagram kullanımında dünyada 6. sırada olduğu istatistiğiyle (Kemp, 2018) uyumlu olduğu görülmüştür. Ankete katılan üniversite öğrencilerinin haber alma konusundaki birinci tercihlerinin, aslen bir haber verme platformu olmayan "Instagram" olması ise, gençlerin sosyal medya üzerinden bilgilenme/haber alma ihtiyaçlarını bile boş zaman geçirme ve arkadaşlarla iletişime geçme amaçlı bir sosyal medya uygulaması üzerinden gidermeye çalıştıklarını göstermektedir.

Gençlerin sosyal medyayı kullanım amaçlarına yakından bakıldığında ise, eğlence, iletişim, gündem takibi, mesajlaşma ve boş zaman değerlendirme faaliyetlerinin ön plana çıktığ1 görülmektedir. Bilgiye erişim ve bilgi paylaşımı gibi sosyal medyanın kişisel gelişimi destekleyici kullanım amaçlarının ise daha düşük düzeyde kaldığ1 görülmüştür.

Sosyal medya bağımlılı̆̆ı hususuna gelindiğinde ise, öncelikle, sosyal medyada geçirilen sürenin artmasıyla sosyal medya bağımlılık düzeyinin de arttı̆̆ı bulgusu ortaya çıkmaktadır. Bunun yanında çalışmada, Filiz ve diğerlerinin (2014) internet bağımlılığı araştırmasıyla paralel şekilde, sosyal medya bağımlılığı düzeyleri hususunda kadın ve erkekler arasında anlamlı bir farklılık olmadığı görülmüştür. Sosyal medya kullanım amaçları ile sosyal medya bağımlılığı ilişkisine bakıldığında ise, "boş zaman değerlendirme" amacı ile sosyal medya bağımlılığı arasında pozitif bir ilişki olduğu görülmüştür. Bu sonuç Sofiah ve diğerlerinin (2011), Chen ve Kim'in (2013) ve Ryan ve diğerlerinin (2014) sosyal medya kullanicisı üniversite öğrencileri ile yaptıkları araştırmaların sonuçlarıyla paralellik arz etmektedir. Buna göre, sosyal medyayı boş zaman değerlendirme amacıyla sıklıkla kullanan gençlerin sosyal medya bağımlılık düzeyleri de artmaktadır. Eğlence amacıyla sosyal medya kullanımı ile bağımlılık arasında ortaya çıkan pozitif ilişki de Punyanunt-Carter ve diğerlerinin (2017) Snapchat kullanan gençlere yönelik araştırmasıyla benzer sonuçları işaret etmektedir.

Boş zaman değerlendirme amacının hemen ardından, "insanları daha iyi tanıma" ve "fikir alışverişinde bulunma" gibi sosyalleşme ihtiyacına dönük sosyal medya kullanım amaçları ile sosyal medya bağımlılığı arasında pozitif bir ilişki olduğu görülmüştür. Bu sonuçlar da Akın'ın (2017) ve Filiz ve diğerlerinin (2014) Türkiye'deki sosyal medya kullanıcısı gençlerin sosyal medya bağımlılıkları ile ilgili araştırmalarıyla uyumlu gözükmektedir. Sonuçta, konuya Türkiye'deki sosyal medya kullanıcısı gençler özelinde baktığımızda, daha önceki araştırmalarda ortaya çıkan ve sosyalleşme ihtiyacına işaret eden kullanımın yanı sıra, "boş zaman değerlendirme" ve "eğlence" amaçlı kullanımların da sosyal medya bağımlılığı ile pozitif bir ilişki içerisinde olduğu bu çalışma ile ortaya koyulmuştur.

İdeal olarak internet ve sosyal medya, boş zaman geçirme ve eğlence gibi anlık/geçici işlevlerinin dışında, bilgi edinme ve kişisel gelişim/eğitim (Korgaonkar ve Wolin, 1999; Papacharissi ve Rubin, 2010), diğer kullanıcılarla etkileşime girme ve bilgi paylaşımı (Shao, 
2009; Sandoval ve Fuchs, 2010), eğitim süreçlerini iyileştirme (Moran ve diğerleri, 2011; Tess, 2013) ve çevrim içi kamuoyu vasıtasıyla özellikle gençlere sosyo-politik konulara/sorunlara aktif katılım göstererek demokratik kültüre katkı yapma (Dahlgren, 2009; Bouilanne, 2015) olanaklarını sunmaktadır. Ancak sosyal medyanın bu olumlu işlevlerinin yerini salt boş zaman geçirme, arkadaşlarla mesajlaşma ve eğlence amaçları aldığında kişisel (ruhsal) ve toplumsal sorunları tetikleyen sosyal medya bağımlığının da arttığı görülmektedir. Bu noktada, özellikle gençlerin sosyal medyanın sağlıklı kullanımı ve sanal mecralarda fazla vakit geçirmenin doğurabileceği riskler konusunda bilgilendirilmeleri önem arz etmektedir. Dijital okuryazarlık olarak da adlandırılan bu sürecin eğitim sistemine üniversite öncesinde de entegre edilmesi, böylece boş zaman değerlendirme ve eğlence amaçlı sosyal medya kullanımının kısıtlanması ve bilgi edinme, eğitim-öğretimi destekleme ve toplumsal katma değeri olan bilgi paylaşımı gibi kullanımların özendirilmesi gerekmektedir. Böylece, sosyal medya kullanım amaçları ile ilgili bilinç düzeyinin erken yaşlardan itibaren yükseltilmesi ile birlikte, bireyleri ve toplumu tehdit eden sosyal medya bağımlılığ sorununun kontrol altına alınabileceği düşünülmektedir.

\section{Kaynakça}

Akın, M. (2017). A research on the impacts of the young people's Internet addiction levels and their social media preferences. International Review of Management and Marketing, 7(2), 256-262.

Andreassen, C. S., Torsheim, T., \& Pallesen, S. (2014). Predictors of use of social network sites at work-a specific type of cyberloafing. Journal of Computer-Mediated Communication, 19(4), 906-921.

Aydın, İ. E. (2016). Üniversite öğrencilerinin sosyal medya kullanımları üzerine bir araştırma: Anadolu Üniversitesi örneği. Selçuk Üniversitesi Sosyal Bilimler Enstitüsü Dergisi, 35, 373-386.

Boulianne, S. (2015). Social media use and participation: A meta-analysis of current research. Information, Communication \& Society, 18(5), 524-538.

Boyd, D. M., \& Ellison, N. B. (2007). Social network sites: Definition, history, and scholarship. Journal of Computer-mediated Communication, 13(1), 210-230.

Chen, H.T. \& Kim, Y. (2013). Problematic use of social network sites: the interactive relationship between gratifications sought and privacy concerns. Cyberpsychology, Behavior, and Social Networking, 16, 806-812.

Çelik, M. (2017). Üniversite öğrencilerinin sosyal medya bağımlılı düzeylerinin incelenmesi: Kültür Üniversitesi öğrencileri üzerinde bir araştırma. 1. Uluslararası İletişimde Yeni Yönelimler Konferansı. İstanbul Ticaret Üniversitesi, Halkla İlişkiler ve Reklamcılık Bölümü, İstanbul.

Dahlgren, P. (2009). Media and political engagement: Citizens, communication, and democracy. Cambridge: Cambridge University Press.

Davies, T. \& Cranston, P. (2008). Youth work and social networking: Interim report. Leicester: National Youth Agency. 
Filiz, O., Erol, O., Dönmez, F. İ., \& Kurt, A. A. (2014). BÖTE bölümü öğrencilerinin sosyal ağ siteleri kullanım amaçları ile internet bağımlılıkları arasındaki ilişkinin incelenmesi. Journal of Instructional Technologies \& Teacher Education, 3(2), 17-28.

Floros, G. \& Siomos, K. (2013). The relationship between optimal parenting, Internet addiction and motives for social networking in adolescence. Psychiatry Research, 209(3), 529-534.

Griffiths, M. D. (2005). A 'components' model of addiction within a biopsychosocial framework. Journal of Substance Use, 10, 191-197.

Griffiths, M. D. (2012). Facebook addiction: Concerns, criticisms and recommendations. Psychological Reports, 110, 518-520.

Günüç, S. (2009). İnternet bağımlılık ölçeğinin geliştirilmesi ve bazı demografik değişkenler ile internet bă̆gmlılığı arasındaki ilişkilerin incelenmesi. (Yüksek Lisans Tezi, Yüzüncü Yıl Üniversitesi, Van.)

Kemp, S. (2018). Digital in 2018: World's Internet Users Pass the 4 Billion Mark. We Are Social. 01.02.2019, Retrieved from: https://wearesocial.com/blog/2018/01/global-digital-report$\underline{2018}$

Kırık, A. M., Arslan, A., Çetinkaya, A., \& Gül, M. (2015). A quantitative research on the level of social media addiction among young people in Turkey. International Journal of Science Culture and Sport (IntJSCS), 3(3), 108-122.

Koçer, M. (2012). Erciyes Üniversitesi öğrencilerinin İnternet ve sosyal medya kullanım alışkanlıkları. Akdeniz Üniversitesi İletişim Fakültesi Dergisi, 18, 70-85.

Korgaonkar, P. K. \& Wolin, L. D. (1999). A multivariate analysis of web uses. Journal of Advertising Research, 39(1), 53-68.

Köseoğlu, Ö. (2012). Sosyal ağ sitesi kullanıcılarının motivasyonları: Facebook üzerine bir araştırma. Selçuk Üniversitesi İletişim Fakültesi Akademik Dergisi, 7(2), 58-81.

Kuss, D. J. \& Griffiths, M. D. (2011b). Online social networking and addiction - A review of the psychological literature. International Journal of Environmental Research and Public Health, 8, 3528-3552.

Küçükali, A. (2016). Üniversite öğrencilerinin sosyal medya kullanımı: Atatürk Üniversitesi örneği. Bartın Üniversitesi İIBF Dergisi, 7(13), 531-546.

Lee, Z. W., Cheung, C. M., \& Thadani, D. R. (2012). An investigation into the problematic use of Facebook. Proceedings of the 45th Hawaii International Conference on System Sciences, Maui, HI, USA, 1768-1776.

Moran, M., Seaman, J., \& Tinti-Kane, H. (2011). Teaching, learning, and sharing: How today's higher education faculty use social media. Pearson Learning Solutions and Babson Survey Research Group, 1-32.

Palfrey, J. \& Gasser, U. (2008). Born digital: Understanding the first generation of digital natives. Basic Books. 01.02.2019, Retrieved from: https://pages.uoregon.edu/koopman/courses readings/phil123-net/identity/palfreygasser born-digital.pdf 
Pantic, I. (2014). Online social networking and mental health. Cyberpsychology, Behavior, and Social Networking, 17(10), 652-657.

Papacharissi, Z. \& Rubin, A. M. (2000). Predictors of Internet use. Journal of Broadcasting $\mathcal{E}$ Electronic Media, 44, 175-196.

Punyanunt-Carter, N. M., De La Cruz, J. J., \& Wrench, J. S. (2017). Investigating the relationships among college students' satisfaction, addiction, needs, communication apprehension, motives, and uses \& gratifications with Snapchat. Computers in Human Behavior, 75, 870-875.

Rumpf, H.-J., Meyer, C., Kreuzer, A., John, U. \& Meerkerk, G.-J. (2011). Prävalenz der Internetabhängigkeit (PINTA). Bericht an das Bundesministerium für Gesundheit. Verfügbar über. 01.02.2019, Retrieved from: http://www.drogenbeauftragte.de/fileadmin/dateiendba/DrogenundSucht/Computerspiele_Internet/Downloads/PINTA-BerichtEndfassung 280611.pdf

Ryan, T., Chester, A., Reece, J., \& Xenos, S. (2014). The uses and abuses of Facebook: A review of Facebook addiction. Journal of behavioral addictions, 3(3), 133-148.

Sandoval, M., \& Fuchs, C. (2010). Towards a critical theory of alternative media. Telematics and Informatics, 27(2), 141-150.

Shao, G. (2009). Understanding the appeal of user-generated media: a uses and gratification perspective. Internet research, 19(1), 7-25.

Sofiah, S. Z. S., Omar, S. Z., Bolong, J., \& Osman, M. N. (2011). Facebook addiction among female university students. Revista De Administratie Publica Si Politici Sociale, 3(7), 95.

Solmaz, B., Tekin, G., Herzem, Z., \& Demir, M. (2013). İnternet ve sosyal medya kullanımı üzerine bir uygulama. Selçuk Üniversitesi İletişim Fakültesi Akademik Dergisi, 7(4), 23-32.

Statista. (2019). Negative effects of using social media according to Italian users in 2017. 01.02.2019, Retrieved from: https://www.statista.com/statistics/866186/negative-effects-ofsocial-media-usage-in-italy/3

Şahin, C. \& Yağcl, M. (2017). Sosyal medya bağımlılı̆̆ı ölçeği-yetişkin formu: Geçerlilik ve güvenirlik çalışması. Ahi Evran Üniversitesi Kırşehir Eğitim Fakültesi Dergisi (KEFAD), 14(1), 523-538.

Tektaş, N. (2014). Üniversite öğrencilerinin sosyal ağları kullanımlarına yönelik bir araştırma. Tarih Okulu Dergisi, 2014(XVII).

Tess, P. A. (2013). The role of social media in higher education classes (real and virtual) - A literature review. Computers in Human Behavior, 29(5), 60-68.

Utz, S., Muscanell, N., \& Khalid, C. (2015). Snapchat elicits more jealousy than Facebook: A comparison of Snapchat and Facebook use. Cyberpsychology, Behavior, and Social Networking, 18(3), 141-146.

Valkenburg, P.M. \& Peter, J. (2011). Adolescents' online communication: an integrated model of its attraction, opportunities, and risks. Journal of Adolescent Health, 48, 121-127. 
Van Rooij, A. J. \& Schoenmakers, T. M. (2013). Monitor Internet en Jongeren 2010-2012. Het (mobiele) gebruik van sociale media en games door jongeren [Monitor Internet and Youth 2010-2012: The (mobile) use of social media and games by adolescents] 01.02.2019, Retrieved from: http://www.ivo.nl/UserFiles/File/Publicaties/201301\%20Factsheet $\% 20$ Social\%20media $\% 20$ en\%20gamen.pdf

Van Rooij, A. J., Schoenmakers, T. M., Van de Eijnden, R. J., \& Van de Mheen, D. (2010). Compulsive Internet use: The role of online gaming and other Internet applications. The Journal of Adolescent Health, 47(1), 51-57.

Wan, C. (2009). Gratifications $\mathcal{E}$ loneliness as predictors of campus-SNS websites addiction $\mathcal{E}$ usage pattern among Chinese college students (Master's thesis). Hong Kong: The Chinese University of Hong Kong.

\section{Ekler}

Ek 1. Sosyal Medya Kullanım Amaçları Ölçeği

\begin{tabular}{|c|c|c|c|c|c|c|}
\hline No & & 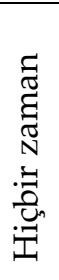 & 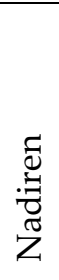 & 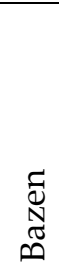 & $\frac{\frac{\pi}{5}}{\frac{\pi}{5}}$ & 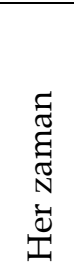 \\
\hline 1 & $\begin{array}{l}\text { Sosyal medyayı arkadaşlarla iletişimde bulunmak } \\
\text { için kullanırım. }\end{array}$ & & & & & \\
\hline 2 & $\begin{array}{l}\text { Sosyal medyayı eğlenmek ve rahatlamak için } \\
\text { kullanırım. }\end{array}$ & & & & & \\
\hline 3 & $\begin{array}{l}\text { Sosyal medyayı boş zamanları değerlendirmek } \\
\text { için kullanırım. }\end{array}$ & & & & & \\
\hline 4 & Sosyal medyayı müzik dinlemek için kullanırım. & & & & & \\
\hline 5 & $\begin{array}{l}\text { Sosyal medyayı mesaj göndermek ve almak için } \\
\text { kullanırım. }\end{array}$ & & & & & \\
\hline 6 & $\begin{array}{l}\text { Sosyal medyayı insanları daha iyi tanımak için } \\
\text { kullanırım. }\end{array}$ & & & & & \\
\hline 7 & $\begin{array}{l}\text { Sosyal medyayı olayları/gündemi takip etmek için } \\
\text { kullanırım. }\end{array}$ & & & & & \\
\hline 8 & $\begin{array}{l}\text { Sosyal medyayı kişisel sunum ve bilgi paylaşımı } \\
\text { için kullanırım. }\end{array}$ & & & & & \\
\hline 9 & $\begin{array}{l}\text { Sosyal medyayı kişi ve organizasyonlara ulaşmak } \\
\text { için kullanırım. }\end{array}$ & & & & & \\
\hline 10 & $\begin{array}{l}\text { Sosyal medyayı fikir alışverişinde bulunmak için } \\
\text { kullanırım. }\end{array}$ & & & & & \\
\hline 11 & $\begin{array}{l}\text { Sosyal medyayı bilgiye erişim amacıyla } \\
\text { kullanırım. }\end{array}$ & & & & & \\
\hline
\end{tabular}


Gençlerin Sosyal Medya Kullanım Amaçları ile Sosyal Medya Bağımlılığı İlişkisinin İncelenmesi

Ek 2. Sosyal Medya Bağımlılı̆̆

\begin{tabular}{|c|c|c|c|c|c|c|}
\hline No & & 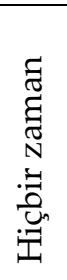 & 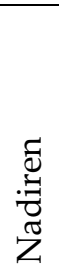 & $\begin{array}{l}\text { Фี } \\
\text { స్ } \\
\text { صే }\end{array}$ & $\frac{\frac{\pi}{\sqrt{3}}}{\frac{\vec{y}}{5}}$ & 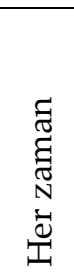 \\
\hline 1 & $\begin{array}{l}\text { Sosyal medyayı kullanmamdan dolayı ailem ile } \\
\text { sorunlar yaşarım. }\end{array}$ & & & & & \\
\hline 2 & $\begin{array}{l}\text { Sosyal medyayı kullanmamdan dolayı başka } \\
\text { etkinliklere (spor, kitap okuma vb.) ilgim azalır. }\end{array}$ & & & & & \\
\hline 3 & $\begin{array}{l}\text { Sosyal medyayı kullanmamdan dolayı ev/iş/okul } \\
\text { sorumluluklarımı ihmal ederim. }\end{array}$ & & & & & \\
\hline 4 & $\begin{array}{l}\text { Sosyal medyayı kullanmamdan dolayı ailem ile } \\
\text { daha az zaman geçiririm. }\end{array}$ & & & & & \\
\hline 5 & $\begin{array}{l}\text { Sosyal medyayı kullanmamdan dolayı } \\
\text { arkadaşlarım ile daha az zaman geçiririm. }\end{array}$ & & & & & \\
\hline 6 & $\begin{array}{l}\text { Çevremdekiler sosyal medyada harcadığım } \\
\text { zamandan dolayı şikâyet eder. }\end{array}$ & & & & & \\
\hline 7 & $\begin{array}{l}\text { Arkadaşlarım beni çağırsa dahi sosyal medyanın } \\
\text { başından kalkamam. }\end{array}$ & & & & & \\
\hline
\end{tabular}

